\title{
Erratum to "Stress Management in Parents of Children with Diabetes Type 1: A Randomized Controlled Trial", [Psychology 6 (2015) 1040-1050]
}

\author{
Niki S. Pateraki ${ }^{*}$, Evaggelia Mantzourani ${ }^{2}$, Panagiota P. Darvyri1 ${ }^{*}$, Evangelos C. Alexopoulos ${ }^{1}$, \\ Liza Varvogli' ${ }^{1}$, Dimitrios Mamoulakis ${ }^{2}$, Darviri Christina ${ }^{1 \#, ~ G e o r g e ~ P . ~ C h r o u s o s ~}{ }^{1,3 \#}$ \\ ${ }^{1}$ Postgraduate Course Science of Stress and Health Promotion, School of Medicine, University of Athens, Athens, Greece \\ ${ }^{2}$ General Hospital of Heraklion, Crete, Greece \\ ${ }^{3}$ First Department of Pediatrics, Children's Hospital Aghia Sofia, School of Medicine, University of Athens, Athens, Greece \\ Email: *nikipateraki@hotmail.com, *pandarviri@yahoo.gr
}

Received: December 2, 2020 Accepted: January 22, 2021

Published: January 25, 2021

Copyright (C) 2021 by author(s) and Scientific Research Publishing Inc. This work is licensed under the Creative Commons Attribution International License (CC BY 4.0).

http://creativecommons.org/licenses/by/4.0/
The original online version of this article (Pateraki, N. S., Mantzourani, E., Darvyri, P. P, Alexopoulos, E. C., Varvogli, L., Mamoulakis, D., Christina, D., \& Chrousos, G. P. (2015). Stress Management in Parents of Children with Diabetes Type 1: A Randomized Controlled Trial. Psychology, 6, 1040-1050. http://dx.doi.org/10.4236/psych.2015.68101) needs to add the following items.

- 2.4. In Baseline and Outcome Measures fourth paragraph the names of the Greek authors that standardized the scale (G. N. Lyrakos, C. Arvaniti, M. Smyrnioti \& G. Kostopanagiotou, 2011).

- 3.2. Primary Endpoint Analyses to the last sentence The instrument has been standardized for Greek populations (G. N. Lyrakos, C. Arvaniti, M. Smyrnioti \& G. Kostopanagiotou, 2011).

- Reference (G. N. Lyrakos, C. Arvaniti, M. Smyrnioti \& G. Kostopanagiotou, 2011. P03-561-Translation and Validation Study of the depression anxiety stress scale in the Greek general population and in psychiatric patient's sample. European Psychiatry, 26, 1731). doi:10.1016/S0924-9338(11)73435-6. 